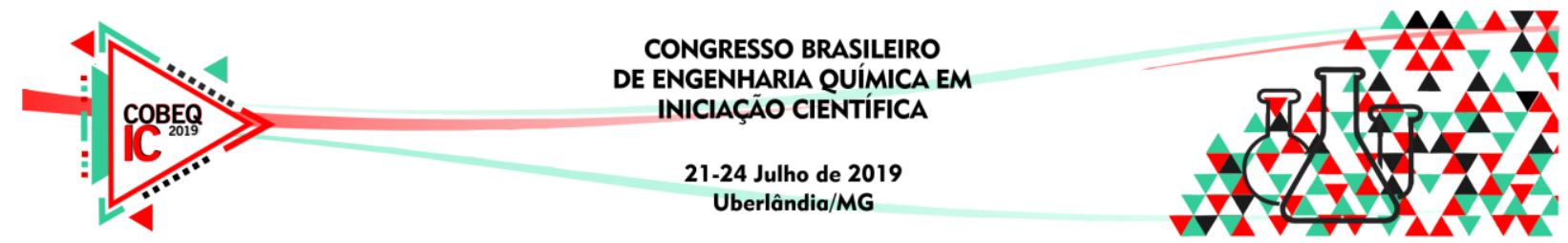

\title{
ANÁLISE DA QUALIDADE FÍSICO-QUÍMICA E MICROBIOLÓGICA DO LEITE CRU ADMITIDO EM LATICÍNIO DA REGIÃO DE VAZANTE-MG
}

\author{
K. P. RIBEIRO ${ }^{1}$, H. R. L. VIEIRA ${ }^{2}$ e G.C.S. POMPÊU ${ }^{1}$ \\ ${ }^{1}$ Universidade Federal de Uberlândia, Instituto de Química, Programa de Pós-Graduação em \\ Biocombustíveis \\ ${ }^{2}$ Centro Universitário de Patos de Minas, Departamento de Engenharia Química \\ E-mail para contato: karol18ribeiro@hotmail.com
}

\begin{abstract}
RESUMO - O leite é consumido na alimentação humana em grande escala pelo mundo todo, sendo um produto bastante perecível e, portanto, é primordial acompanhar sua qualidade. Este controle é realizado por meio de análises rotineiras nos laticínios para garantir segurança e qualidade aos consumidores. Deste modo, este trabalho foi desenvolvido com o intuito de avaliar as amostras de leite cru obtidas na época chuvosa e na seca, e observar a influência do clima sob a qualidade do leite. As amostras foram coletadas na cidade de Vazante-MG, e foram submetidas à análises físico-químicas e microbiológicas, verificando se os limites das análises em legislação são coerentes com a prática do dia-a-dia. As análises comprovaram que o intemperismo não influencia consideravelmente a qualidade do leite. Contudo, foram encontradas alterações da prova do álcool, alizarol e coliformes totais fora do permitido pela legislação, indicando possíveis fraudes nas amostras. Conclui-se ainda que houve falhas no recebimento do leite no laticínio, tendo em vista que na amostra 3 houve instabilidade durante todos os meses analisados, e o leite continuou sendo recebido. A diversidade das amostras obtidas foi de suma importância, pois detectou problemas na qualidade do leite e na recepção deste por parte do laticínio.
\end{abstract}

\section{INTRODUÇÃO}

A produção de leite no Brasil, segundo Pinto et al (2011) é considerada uma das principais atividades agropecuárias fornecedoras de alimento à população, sendo um dos principais setores de geração de renda nacional e arrecadação tributária. Ferreira, Perez e Abrantes (2007) relatam que o Brasil é um dos grandes produtores mundiais de leite, sendo responsável por 4,4\% da produção mundial com 23,3 bilhões de litros.

Por oferecer uma equilibrada composição de nutrientes que resulta um elevado valor biológico, o leite é considerado um dos mais completos alimentos in natura. Industrializado, resulta em diversos tipos para consumo, devidamente controlados por normas de inspeção industrial e sanitária (TRONCO, 2013).

Os produtos lácteos são o grupo de alimentos derivados do leite, incluindo o próprio. Para a fabricação desses produtos é necessário que o leite apresente características físico- 


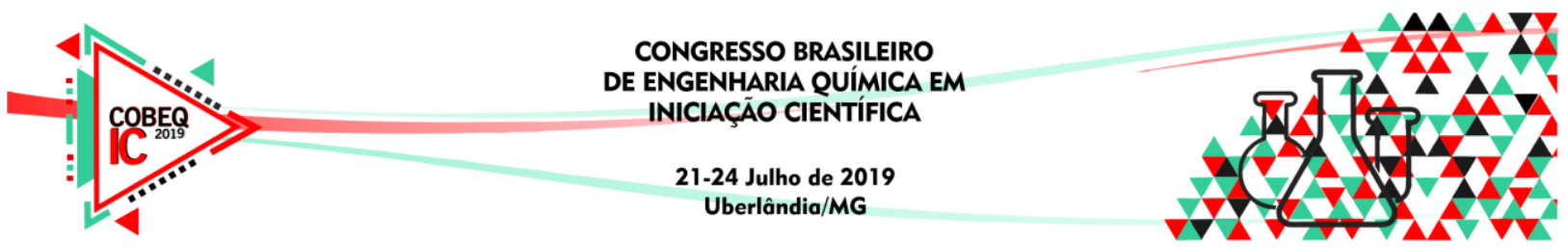

químicas e microbiológicas satisfatórias para garantir a segurança e qualidade do produto. Assim, no momento da chegada do leite cru ao laticínio são realizadas análises a fim de identificar suas características. Estas dependem de vários fatores, temperatura, acondicionamento e alimentação das vacas.

O leite só é considerado de boa qualidade quando é propriamente obtido e processado. A insatisfação do leite produzido no Brasil é um problema social, econômico e cultural. Apesar da grande importância que o leite representa, não tem recebido atenção necessária (CHAPAVAL, 2000). Desta maneira, é fundamental o controle da qualidade físico-química e microbiológica do leite que chega à plataforma de recepção da indústria, constituindo-se num procedimento de rotina, garantindo assim a saúde da população (TRONCO, 2015).

A normatização da produção de leite tem passado mudanças nos últimos anos, sendo fato que o leite cru produzido no Brasil apresenta baixa qualidade. A contaminação do leite inicia-se na ordenha e pode ocorrer por muitos fatores, como higiene de equipamentos e manipuladores, qualidade da água e sanidade do rebanho. A aplicação de boas práticas é imprescindível para minimizar os riscos de contaminação nas etapas dos processos. (FERREIRA, 2017).

Segundo Castanheira (2012) os métodos físico-químicos avaliam a composição química do leite, incluindo métodos qualitativos (presença/ausência de substâncias estranhas) e semiquantitativas (determinação dos teores de constituintes principais). São aplicadas também medidas de propriedades físicas, como densidade, ponto de congelamento e $\mathrm{pH}$, para caracterização do leite. O presente trabalho teve como objetivo avaliar as características físico-químicas e microbiológicas do leite cru admitido em laticínio na região de Vazante-MG referente ao primeiro e ao segundo semestre de 2017. Deste modo foi possível avalia a qualidade do leite admitido no laticínio bem como o rigor das análises realizadas neste.

\section{METODOLOGIA}

O trabalho foi desenvolvido durante maio a novembro de 2017 , avaliando amostras obtidas na época chuvosa e seca, a fim de observar a influência do intemperismo sob a qualidade do leite. As análises qualitativas e quantitativas foram realizadas no laboratório de Bioquímica e Microbiologia do Centro Universitário de Patos de Minas. As amostras foram coletadas em um laticínio localizado em Vazante-MG, utilizando frascos de vidros esterilizados, sendo coletadas diretamente do tanque de recepção. Após a coleta, as amostras foram acondicionadas em recipientes térmicos, transportadas e acondicionadas sob refrigeração nos respectivos laboratórios de análise.

A caracterização das análises foi dividida em duas etapas: análises físico-químicas e microbiológicas. A primeira, baseada em avaliar a prova de álcool, análise de alizarol, determinação de acidez titulável, densidade, presença de amido e de cloretos, neutralizantes de acidez, formaldeído, teor de gordura, fosfatase alcalina, peroxidade, sacarose, $\mathrm{pH}$, resíduos de antibióticos em leite e ponto de congelamento. Na segunda etapa, as análises focadas em microbiologia estavam direcionadas para avaliação de coliformes totais. Todas as análises seguiram metodologia de Castanheira (2012). 


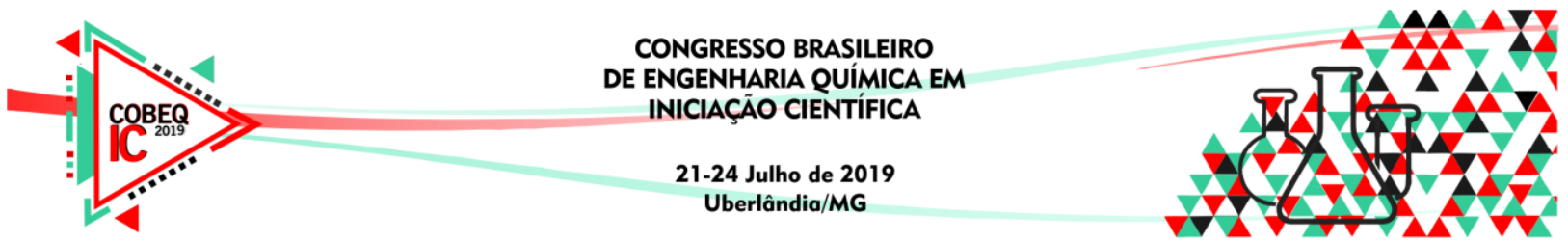

\section{RESULTADOS E DISCUSSÃO}

De acordo com o Art. 476 Inspeção Industrial e Sanitária do Leite e Derivados (BRASIL, 2017) considera-se leite normal, o produto que apresente os padrões de qualidade descritos na Tabela 1.

Tabela 1 - Requisitos de qualidade do leite cru

\begin{tabular}{|l|c|}
\hline \multicolumn{1}{|c|}{ Requisitos } & Referências \\
\hline Aspecto e cor & Líquido branco/ligeiramente amarelado, homogêneo e sem partículas/substâncias estranhas. \\
\hline Sabor e odor & Ausência de sabores/odores estranhos \\
\hline \multicolumn{2}{|c|}{ Requisitos gerais } \\
\hline \multicolumn{2}{|c|}{ Ausência de neutralizantes da acidez e reconstituintes de densidade; } \\
Ausência de resíduos de antibióticos ou de outros medicamentos/produtos de uso veterinário. \\
\hline \multicolumn{2}{|c|}{ Requisitos Físicos e Químicos } \\
\hline Matéria Gorda & Teor original, com o mínimo de $3,0 \mathrm{~g} / 100 \mathrm{~g}$ \\
\hline Densidade $(\mathrm{g} / \mathrm{mL})$ & 1,028 a 1,034 \\
\hline Acidez $\left({ }^{\circ}\right.$ Dornic) & $15-20$ \\
\hline Crioscopia & Máximo - $0,530^{\circ} \mathrm{H}\left(\right.$ equivalente a $\left.-0,512{ }^{\circ} \mathrm{C}\right)$ \\
\hline pH & Entre $6,2-6,8$ \\
\hline
\end{tabular}

\subsection{Análises Físico-Químicas}

Os resultados obtidos nas análises físico-químicas do leite cru estão descritos na Tabela 2. Obteve-se instabilidade nas amostras 3, em todos os meses, referente a prova do álcool. Na prova do Alizarol observou-se instabilidade nas amostras 1 e 2 nos meses de julho e setembro, o que demonstra pouca resistência no mesmo, podendo haver formação de grumos e coágulos grandes. Esse fato pode estar associado à alta concentração de microrganismos mesófilos no leite, lavando o aumento da acidez (CASTANHEIRA, 2012).

Tabela 2 - Análises de Recepção do Leite Cru

\begin{tabular}{|c|c|c|c|c|}
\hline Amostras & \multicolumn{5}{|c|}{ Período } \\
\hline \hline & Março & Maio & Junho & Setembro \\
\hline \hline \multicolumn{5}{|c|}{ Álcool } \\
\hline Amostra 1 & Normal & Normal & Normal & Normal \\
\hline Amostra 2 & Normal & Normal & Normal & Normal \\
\hline Amostra 3 & Instável & Instável & Instável & Instável \\
\hline \multicolumn{5}{|c|}{ Alizarol } \\
\hline Amostra 1 & Normal & Normal & Normal & Instável \\
\hline Amostra 2 & Normal & Normal & Normal & Instável \\
\hline Amostra 3 & Normal & Normal & Normal & Normal \\
\hline \multicolumn{5}{|c|}{ Acidez Titulável ('ํDornic) } \\
\hline Amostra 1 & 18 & 18 & 18 & 18 \\
\hline Amostra 2 & 15 & 14 & 17 & 18 \\
\hline Amostra 3 & 19 & 19 & 19 & 19 \\
\hline
\end{tabular}

Pelas amostras serem consecutivas e do mesmo produtor, a variação não poderia ter ocorrido. Segundo Tronco (2008), esta variação pode ser explicada pela refrigeração inadequada após a ordenha. Estes detalhes acarretam diretamente na perda de qualidade do produto, e consequentemente na perda econômica. A prova do Alizarol mostra-se mais eficiente do que a prova do álcool, por fornecer tanto estabilidade, quanto uma estimativa da acidez do leite e por auxiliar também na detecção de fraudes por adição de neutralizantes da 


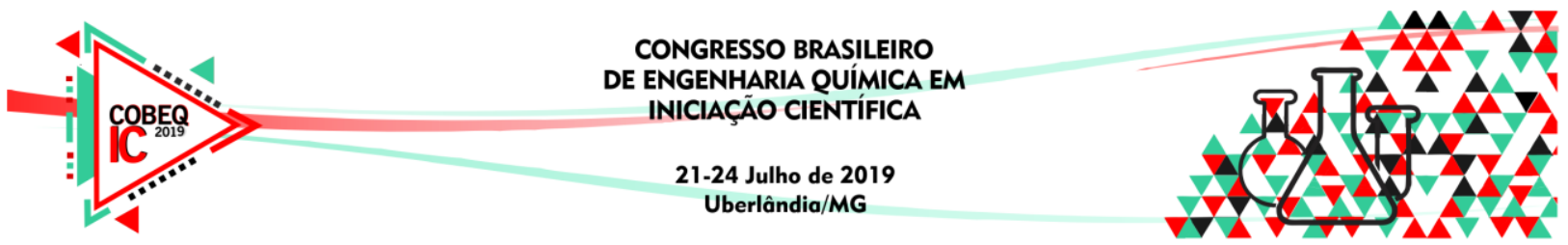

acidez, ou de água, através da coloração roxa, atípica num leite de acidez normal. O teste do álcool também verifica efeitos de acidez elevada ou de desequilíbrio salino, porém não avalia o nível de acidez do leite, por não possuir o indicador de $\mathrm{pH}$, a alizarina.

Na acidez titulável os resultados obtidos referentes às amostras de março a setembro, foram satisfatórias, tendo em vista que está de acordo com a legislação, de 14 a $18{ }^{\circ}$ Dornic, comprovando assim, que o leite se encontra em boas condições higiênicas e de refrigeração, desde a ordenha até a chegada na indústria (CASTANHEIRA 2012).

Conforme observado na Tabela 3, as análises realizadas no decorrer do ano em relação às fraudes no leite, deram todas negativas, comprovando assim que o leite está livre de substâncias que ocultam evidências de sua má qualidade. Segundo RIISPOA (BRASIL, 2017): "considera-se impróprio para consumo humano direto o leite que esteja fraudado. (Inciso V).

Tabela 3 - Pesquisa de fraudes

\begin{tabular}{|c|c|c|c|c|}
\hline Amostras & \multicolumn{4}{|c|}{ Período } \\
\hline \hline & Março & Maio & Junho & Setembro \\
\hline \hline \multicolumn{5}{|c|}{ Cloretos (sal) } \\
\hline Amostra 1 & Negativo & Negativo & Negativo & Negativo \\
\hline Amostra 2 & Negativo & Negativo & Negativo & Negativo \\
\hline Amostra 3 & Negativo & Negativo & Negativo & Negativo \\
\hline \multicolumn{5}{|c|}{ Amido } \\
\hline Amostra 1 & Negativo & Negativo & Negativo & Negativo \\
\hline Amostra 2 & Negativo & Negativo & Negativo & Negativo \\
\hline Amostra 3 & Negativo & Negativo & Negativo & Negativo \\
\hline \multicolumn{5}{|c|}{ Neutralizantes de Acidez } \\
\hline Amostra 1 & Negativo & Negativo & Negativo & Negativo \\
\hline Amostra 2 & Negativo & Negativo & Negativo & Negativo \\
\hline Amostra 3 & Negativo & Negativo & Negativo & Negativo \\
\hline \multicolumn{5}{|c|}{ Pesquisa de Formaldeído (Formol) } \\
\hline Amostra 1 & Negativo & Negativo & Negativo & Negativo \\
\hline Amostra 2 & Negativo & Negativo & Negativo & Negativo \\
\hline Amostra 3 & Negativo & Negativo & Negativo & Negativo \\
\hline \multicolumn{5}{|c|}{ Pesquisa de Sacarose } \\
\hline Amostra 1 & Negativo & Negativo & Negativo & Negativo \\
\hline Amostra 2 & Negativo & Negativo & Negativo & Negativo \\
\hline Amostra 3 & Negativo & Negativo & Negativo & Negativo \\
\hline \multicolumn{5}{|c|}{ Pesquisa de Resíduos Antibióticos } \\
\hline Amostra 1 & Negativo & Negativo & Negativo & Negativo \\
\hline Amostra 2 & Negativo & Negativo & Negativo & Negativo \\
\hline Amostra 3 & Negativo & Negativo & Negativo & Negativo \\
\hline
\end{tabular}

Os resultados obtidos na avaliação da densidade do leite a $15{ }^{\circ} \mathrm{C}$ (Tabela 4), encontram-se de acordo com a legislação, tendo em vista que a mesma auxilia na identificação de fraudes, principalmente por adição de água. Os resultados obtidos na crioscopia também estão de acordo com legislação, com temperatura apropriada para o super congelamento e sem aguagem. (CASTANHEIRA, 2012).

Tabela 4 - Avaliação das propriedades físico-químicas do leite 


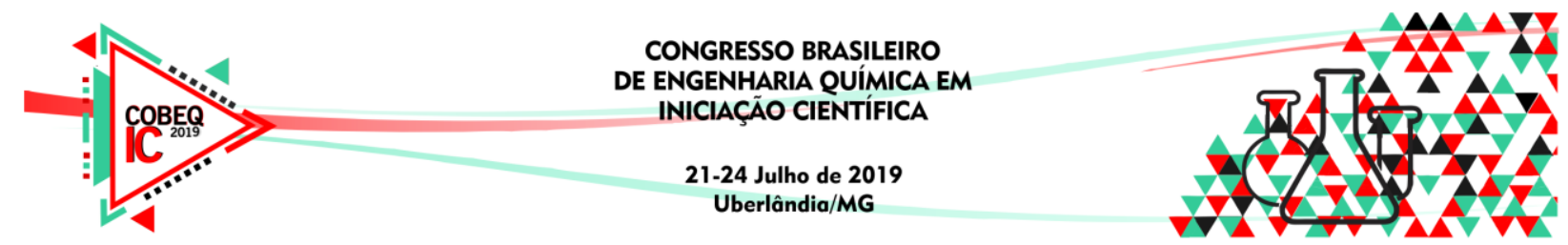

\begin{tabular}{|c|c|c|c|c|}
\hline \hline Amostras & Março & Maio & Junho & Setembro \\
\hline \hline \multicolumn{5}{|c|}{ Densidade a $15^{\circ} \mathrm{C}(\mathrm{g} / \mathrm{mL})$} \\
\hline Amostra 1 & 1,032 & 1,034 & 1,030 & 1,032 \\
\hline Amostra 2 & 1,034 & 1,034 & 1,032 & 1,031 \\
\hline Amostra 3 & 1,028 & 1,028 & 1,028 & 1,028 \\
\hline Depressão do ponto de congelamento (Crioscopia) $\left({ }^{\circ} \mathrm{C}\right)$ \\
\hline Amostra 1 & $-0,500$ & $-0,480$ & $-0,499$ & $-0,510$ \\
\hline Amostra 2 & $-0,510$ & $-0,497$ & $-0,457$ & $-0,505$ \\
\hline Amostra 3 & $-0,512$ & $-0,500$ & $-0,507$ & $-0,503$ \\
\hline
\end{tabular}

Os resultados obtidos no teste de gordura (Tabela 5) encontram-se de acordo com os padrões estabelecidos pela legislação oficial, a Instrução Normativa $n^{\circ} 62 / 11$. O padrão mínimo de gordura para recebimento do leite na plataforma das industrias é de 3,0\%, mas em média, o leite in natura encontra-se com gordura entre $3,0 \%$ a 3,6 \%.

Tabela 5 - Avaliação dos Constituintes do leite

\begin{tabular}{|c|c|c|c|c|}
\hline \hline Amostras & Março & Maio & Junho & Setembro \\
\hline \hline \multicolumn{5}{|c|}{ Gordura (\%) } \\
\hline Amostra 1 & 3,0 & 3,0 & 3,3 & 3,5 \\
\hline Amostra 2 & 3,6 & 3,5 & 3,6 & 3,4 \\
\hline Amostra 3 & 3,6 & 3,6 & 3,5 & 3,5 \\
\hline \multicolumn{5}{|c|}{$\mathrm{pH}$} \\
\hline Amostra 1 & 6,72 & 6,66 & 6,70 & 6,60 \\
\hline Amostra 2 & 6,74 & 6,83 & 6,70 & 6,72 \\
\hline Amostra 3 & 6,55 & 6,50 & 6,60 & 6,60 \\
\hline
\end{tabular}

A Fosfatase Alcalina é considerada positiva, assim como a peroxidade, de acordo com o que a legislação estabelece. Estas análises são utilizadas nos laticínios, como pesquisas no controle da eficiência de tratamentos térmicos, de pasteurização e de esterilização. (Tabela 6).

Tabela 6 - Avaliação de eficiência de tratamento térmico

\begin{tabular}{|c|c|c|c|c|}
\hline \hline Amostras & Março & Maio & Junho & Setembro \\
\hline \hline \multicolumn{5}{|c|}{ Fosfatase alcalina } \\
\hline Amostra 1 & Positivo & Positivo & Positivo & Positivo \\
\hline Amostra 2 & Positivo & Positivo & Positivo & Positivo \\
\hline Amostra 3 & Positivo & Positivo & Positivo & Positivo \\
\hline \multicolumn{5}{|c|}{ Peroxidade } \\
\hline Amostra 1 & Positivo & Positivo & Positivo & Positivo \\
\hline Amostra 2 & Positivo & Positivo & Positivo & Positivo \\
\hline Amostra 3 & Positivo & Positivo & Positivo & Positivo \\
\hline
\end{tabular}

Os resultados obtidos nas análises microbiológicas detectaram a presença de coliformes totais em algumas amostras, como pode ser observado na Tabela 7.

Tabela 7 - Análises microbiológicas

\begin{tabular}{|c|c|c|c|c|}
\hline Amostras & Março & Maio & Junho & Setembro \\
\hline \hline \multicolumn{5}{|c|}{ Coliformes totais } \\
\hline Amostra 1 & Ausência & Ausência & Ausência & Ausência \\
\hline Amostra 2 & Presença & Presença & Presença & Ausência \\
\hline Amostra 3 & Presença & Presença & Ausência & Presença \\
\hline
\end{tabular}

Estes resultados apontam que a presença destes microrganismos patógenos pode provocar odores indesejáveis e até mesmo coagulação do leite. Porém a presença de 


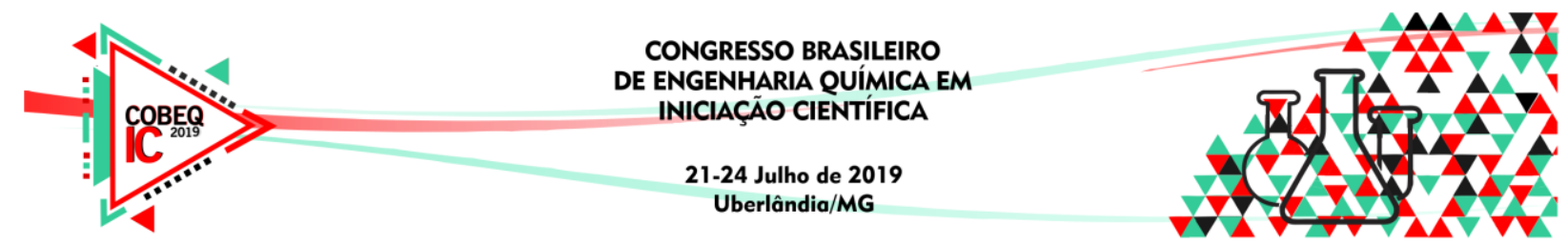

coliformes no leite cru geralmente são inofensivos, pois são destruídos com a pasteurização (CASTANHEIRA, 2012). Foi detectada em duas amostras em períodos consecutivos presença de coliformes no leite, detectando falhas no produtor e no recebimento do laticínio que não tomou providências evidenciando confirmação no teste.

\section{DISPOSIÇÕES GERAIS}

a) o clima não influencia os resultados das análises. Porém houve alterações consideráveis nas análises físico-químicas do álcool e alizarol, além da análise microbiológica de coliformes totais, mostrando que os mesmos se encontram fora dos padrões exigidos pela legislação;

b) conclui-se falhas no recebimento do leite no laticínio, visto instabilidade na amostra 3 durante todos os meses analisados, e o leite continuou sendo recebido. Isso identifica que o leite terá baixa resistência ao aquecimento a que será submetido para tratamento térmico, podendo provocar coagulação e formação de grumos, afetando diretamente a qualidade do produto final comercializado pelo laticínio;

c) a presença de coliformes totais no leite cru pode ser uma indicação de contaminação do leite por microrganismos patógenos que vivem no esterco, como Salmonella e Shigella. Sua presença geralmente indica um sistema de limpeza-desinfecção deficiente;

d) as demais análises foram satisfatórias, constatadas dentro das normas exigidas, assegurando a qualidade da matéria prima e dos produtos lácticos posteriormente produzidos.

\section{REFERÊNCIAS}

BRASIL. Decreto n 30.691 , de 29 de março de 2017. Regulamento da Inspeção Industrial e Sanitária de Produtos de Origem Animal (RIISPOA), Brasília, 29 março, 2017.

CASTANHEIRA, A. C. G. Controle de qualidade de leite e derivados: manual básico. 2. ed. São Paulo: Cap-Lab Indústria e Comércio Ltda, 2012. 367p.

CHAPAVAL, L. Leite de qualidade: Manejo Reprodutivo, Nutricional e Sanitário. Viçosa: Aprenda Fácil, 2000. 195p.

FERREIRA, M. A. M.; PEREZ R.; ABRANTES, L. Agroindústria: leite e derivados: Panorama do Setor de Lácteo. Informe Agropecuário, v.28, n.238, p.8, maio/jun.2017.

TRONCO, V. M. Manual para inspeção da qualidade do leite. 3. ed. Santa Maria: UFSM, 2008.

TRONCO, V. M. Manual para inspeção da qualidade do leite: conceitos fundamentais. 5. ed. Santa Maria: UFSM, 2013. 